\title{
The impact of speculation on the pricing of companies listed on the Warsaw Stock Exchange in light of the ICAPM
}

\section{Introduction}

Research carried out in the 70s showed the compatibility of stock pricing in light of the CAPM (see Fama, MacBeth, 1973). Other works on the return changes often showed deviations from the pricing theory. The cases of incompatible pricing with the classic CAPM are confirmed by Banz (1981), DeBondt and Thaler (1985), and Jegadeesh and Titman (1993). The effect of DeBondt and Thaler is described by the 3-factor Fama-French model, hereafter designated FF (see Fama, French, 1993). However, this model cannot explain the continuation of shortterm returns (see Fama, French, 1995). The said returns anomalies contradict pricing in light of the CAPM.

Research works concerning securities pricing on the Polish market were focused on testing the CAPM and APT applications. These works are presented by Bołt and Miłobędzki (2002), Osińska and Stempińska (2003), Byrka-Kita and Rozkrut (2004), Zarzecki et al. (2004-2005), Czapkiewicz and Skalna (2010), and Gurgul and Wójtowicz (2014), among others. Most of the results contradict the idea that stock pricing is consistent with the pricing that could be observed with CAPM validity. The results of works on the American market are similar.

Urbański (2014) tries to explain the reasons for the incorrect stock pricing in light of the classic CAPM. He shows that if speculative stocks are eliminated, and formed portfolios have spread in average returns, the tested CAPM application generates mean-variance-efficient portfolios.

* AGH University of Science and Technology, Faculty of Management, e-mail: surbansk@zarz.agh. edu.pl 
To my knowledge, there are no studies that examine the influence of speculative stocks on pricing in light of the ICAPM. Therefore, in the paper, I try to prove that the adopted ICAPM applications generate multifactor-efficient portfolios if speculative stocks are excluded from the analysis. Also, I try to "improve" the fitted expected returns (simulated by chosen ICAPM applications) by eliminating the impact of speculation stocks ${ }^{1}$.

The quarterly returns of stocks listed on the Warsaw Stock Exchange (WSE) in 1995-2012 are analyzed. The correct test of ICAPM is based on appropriate forming of portfolios, so I verify the instructions proposed by Cochrane (2001, p. 453), considering the spread in portfolio average returns. For this reason, I further examine whether the returns spread of formed portfolios and speculation stocks, tested in conjunction, affect pricing results.

Summing up, I expect the following conjectures to be true:

\section{Conjecture 1}

The elimination of speculative stocks allows for generating multifactor-efficient portfolios by chosen ICAPM applications.

\section{Conjecture 2}

The elimination of speculative stocks "improves" the fitted expected returns, simulated by chosen ICAPM applications.

\section{Conjecture 3}

Appropriate procedures for the construction of test portfolios have a major impact on stock pricing.

Section 2 presents a fundamental model of portfolio management. Section 3 discusses the procedures of the chosen methods of portfolio forming for three modes of speculative stock influence. Section 4 analyzes the results of pricing in light of the ICAPM using the aggregated three-factor model proposed by Urbański (2012) and the FF model. Section 5 tests the impact of characteristics of the formed portfolios on the explanatory strength of the ICAPM. The final part of the paper presents conclusions.

\section{The model of portfolio management}

Portfolio management procedures should reflect practical investment strategies. FUN defined by equations (1), (2), and (3) represents an investor constructing a portfolio that consists of the best fundamental and undervalued stocks.

\footnotetext{
1 "Improve": here bring them closer to the realized average returns.
} 
The impact of speculation on the pricing of companies...

NUM represents an investor building a portfolio, comprising the best fundamental firms, while $D E N$ represents an investor who purchases undervalued stocks (see Urbanski 2012). Investors construct the portfolios by maximizing FUN and $N U M$ or minimizing $D E N$ (if long investments are considered).

$$
F U N=\frac{N U M}{D E N}=\frac{\operatorname{nor}(R O E) * \operatorname{nor}(A S) * \operatorname{nor}(A P O) * \operatorname{nor}(A P N)}{\operatorname{nor}(M V / E) * \operatorname{nor}(M V / B V)}
$$

where

$$
\begin{gathered}
R O E=F_{1} ; A S=F_{2}=\frac{\sum_{t=1}^{i} S\left(Q_{t}\right)}{\sum_{t=1}^{i} \overline{S\left(n Q_{t}\right)}} ; A P O=F_{3}=\frac{\sum_{t=1}^{i} P O\left(Q_{t}\right)}{\sum_{t=1}^{i} \overline{P O\left(n Q_{t}\right)}} \\
A P N=F_{4}=\frac{\sum_{t=1}^{i} P N\left(Q_{t}\right)}{\sum_{t=1}^{i} \overline{P N\left(n Q_{t}\right)}}, M V / E=F_{5} ; M V / B V=F_{6}
\end{gathered}
$$

$F_{j}(j=1, \ldots, 6)$ are transformed to normalized areas $\left\langle a_{j} ; b_{j}\right\rangle$, according to (3):

$$
\operatorname{nor}\left(F_{j}\right)=a_{j}+\left(b_{j}-a_{j}\right) * \frac{F_{j}-c_{j} * F_{j}^{\min }}{d_{j} * F_{j}^{\max }-c_{j}^{*} F_{j}^{\min }+e_{j}}
$$

In Equations (1), (2) and (3), the corresponding indications are as follows: $R O E$ is return on book equity; $\sum_{t=1}^{i} S\left(Q_{t}\right), \sum_{t=1}^{i} P O\left(Q_{t}\right), \sum_{t=1}^{i} P N\left(Q_{t}\right)$ are values that are accumulated from the beginning of the year as net sales revenue $(S)$, operating profit $(P O)$ and net profit $(P N)$ at the end of " $i$ " quarter $\left(Q_{i}\right)$; $\sum_{t=1}^{i} \overline{S\left(n Q_{t}\right)}, \sum_{t=1}^{i} \overline{P O\left(n Q_{t}\right)}, \sum_{t=1}^{i} \overline{P N\left(n Q_{t}\right)}$ are average values, accumulated from the beginning of the year as $S, P O$ and $P N$ at the end of $Q_{i}$ over the last $n$ years (the present research assumes that $n=3$ years); $M V / E$ is the market-to-earning value ratio; $E$ is the average earning for the last four quarters; $M V / B V$ is the market-to-book value ratio; $a_{j}, b_{j}, c_{j}, d_{j}, e_{j}$ are variation parameters. In equilibrium modeling $F_{j}(j=1, \ldots, 6)$ can be transformed into equal normalized area $<1 ; 2>$ (see Urbański, 2011).

The overall economic interpretation of $F U N$ is presented by Urbański (2011). On the basis of Lakonishok et al. (1994) and FF (1995), I assume that FUN may constitute positive characteristics for the general description of returns. 


\section{Data and forming of testing portfolios}

The study is conducted on the basis of the stocks listed on the WSE in 1995-2012. Data referring to the fundamental results of the inspected companies are taken from the database drawn up by Notoria Serwis Co. Ltd. Data for defining returns on securities is provided by the Warsaw Stock Exchange.

Tested portfolios are based on two procedures. Procedure 1 is proposed by Urbański (2011). In this case, the Cochrane (2001) instructions are used. In procedure 2, portfolios are created in line with FF (1993) methods.

In each procedure, I analyze three modes of samples. Mode M1 considers all WSE stocks except companies characterized by a negative book value. In mode MS1, I eliminate speculative stocks that meet one of the following boundary conditions: a) $M V / B V>100$, b) $R O E<0$ and $B V>0$ and $r_{i t}>0$, c) $M V / B V>30$ and $r_{i t}>0$, where $r_{i t}$ is return of stock $i$ in period $t$. In mode MS2, I eliminate speculative stocks that meet additional condition d) $M V / E<0$. The number of analyzed companies decreased to $21 \%$, after exclusion of speculative stocks MS2 (see Table 1).

Table 1

Number of companies in quantile portfolios

\begin{tabular}{|c|c|c|c|c|c|c|c|c|c|}
\hline \multirow{2}{*}{ Quantile } & \multicolumn{3}{|c|}{ IVQ1996 } & \multicolumn{3}{|c|}{ IVQ2005 } & \multicolumn{3}{|c|}{ IVQ2011 } \\
\hline & M1 & MS1 & MS2 & M1 & MS1 & MS2 & M1 & MS1 & MS2 \\
\hline 1 & 14 & 14 & 13 & 37 & 30 & 29 & 63 & 61 & 50 \\
\hline 2 & 14 & 14 & 13 & 37 & 30 & 29 & 63 & 61 & 50 \\
\hline 3 & 14 & 14 & 13 & 37 & 30 & 29 & 63 & 61 & 50 \\
\hline 4 & 14 & 14 & 13 & 37 & 30 & 29 & 63 & 61 & 50 \\
\hline 5 & 13 & 13 & 13 & 38 & 30 & 30 & 62 & 60 & 49 \\
\hline $\begin{array}{c}\text { Joined } \\
\text { portfolio }\end{array}$ & 69 & 69 & 65 & 186 & 150 & 144 & 314 & 304 & 249 \\
\hline \multicolumn{10}{|c|}{$\begin{array}{l}\text { Notes: In M1, negative- } B V \text { stocks are excluded from the portfolios. Mode MS1 eliminates speculative } \\
\text { stocks that meet one of the following boundary conditions: a) } B V<0 \text { and } M V / B V>100 \text {; b) } B V<0 \\
\text { and } R O E<0 \text { and } r_{i t}>0 ; \text { c) } B V<0 \text { and } M V / B V>30 \text { and } r_{i t}>0 \text {. Mode MS2 eliminates speculative } \\
\text { stocks that meet additional condition d) } M V / E<0 \text {, where } M V \text { is a market value of stock (portfolio), } \\
R O E \text { is the return on book value ( } B V \text { ), } r_{i t} \text { is the return of portfolio } i \text { in period } t, E \text { is the average } \\
\text { earning for the last four quarters. Source: my own research. }\end{array}$} \\
\hline
\end{tabular}


The impact of speculation on the pricing of companies...

Analyzed securities are classified into quantile portfolios built on the basis of $F U N, N U M$, and $D E N$, shown in (1) - in procedure 1 as well as on $B V / M V$ and capitalization $(C A P)$ - in procedure 2. FUN, NUM, DEN, $B V / M V$, and $C A P$ are calculated for all analyzed securities at the beginning of each investment period in which the return is to be calculated. FUN, NUM, DEN, BV/MV, and CAP computed for portfolios constitute average arithmetical values of these functions of various portfolio securities. Returns on the given portfolios are average stock returns weighted by market capitalizations.

The maximal return spreads of portfolio formed on maximal and minimal quantiles are for portfolios formed on FUN, NUM, and DEN, in MS1 and MS2 ( $p$-values $<0,001 \%)$. The spreads for portfolios formed on $B V / M V$ and $C A P$ are lower and insignificantly different from zero ( $p$-values $>10 \%$, see Urbański, 2014).

Table 2 shows the average of market-to-earning and market-to-book ratios, return on book value $(R O E)$, and return on joined quantile portfolios $(r)$ for modes M1, MS1 and MS2.

Table 2

Average values of $M V / E, M V / B V$ and $R O E$ indicators, and return $(r)$ on joined quantile portfolios

\begin{tabular}{|c|c|c|c|c|}
\hline \multirow{2}{*}{ Mode } & \multicolumn{4}{|c|}{ Average quarter values of portfolios } \\
\hline & $\boldsymbol{M} \boldsymbol{V} / \boldsymbol{E}^{*}$ & $\boldsymbol{M V} / \boldsymbol{B V}$ & $\boldsymbol{R O E}$ & $\boldsymbol{r}$ \\
\hline M1 & $\begin{array}{c}35,8 \\
(22.9)\end{array}$ & $\begin{array}{r}2,2 \\
(0.9)\end{array}$ & $\begin{array}{r}4,69 \% \\
(6.57 \%)\end{array}$ & $\begin{array}{r}2,34 \% \\
(16.88 \%)\end{array}$ \\
\hline MS1 & $\begin{array}{c}35,0 \\
(21.7)\end{array}$ & $\begin{array}{c}2,0 \\
(0.8)\end{array}$ & $\begin{array}{r}6,43 \% \\
(7.02 \%)\end{array}$ & $\begin{array}{r}1,44 \% \\
(16.43 \%)\end{array}$ \\
\hline MS2 & $\begin{array}{c}35,0 \\
(21.7)\end{array}$ & $\begin{array}{c}2,0 \\
(0.8)\end{array}$ & $\begin{array}{l}13,44 \% \\
(3.88 \%)\end{array}$ & $\begin{array}{r}2,73 \% \\
(16.00 \%)\end{array}$ \\
\hline \multicolumn{5}{|c|}{$\begin{array}{l}\text { Notes: Stocks in the portfolios are weighted linearly. Standard deviations are indicated below } \\
\text { in brackets. The indicator value for portfolio is determined as an arithmetic mean for stocks } \\
\text { included in the portfolio. Return on given portfolio }(r) \text { is average stock returns weighted by } \\
\text { market capitalizations. In M1, negative- } B V \text { stocks are excluded from the portfolios. Mode MS1 } \\
\text { eliminates speculative stocks that meet one of the following boundary conditions: a) } B V<0 \text { and } \\
\left.M V / B V>100 ; \mathrm{b}) B V<0 \text { and } R O E<0 \text { and } r_{i t}>0 ; \mathrm{c}\right) B V<0 \text { and } M V / B V>30 \text { and } r_{i t}>0 \text {. Mode MS } 2 \\
\text { eliminates speculative stocks that meet additional condition d) } M V / E<0 \text {, where } M V \text { is a market } \\
\text { value of stock (portfolio), } R O E \text { is the return on book value }(B V), r_{i t} \text { is the return of portfolio } i \text { in } \\
\text { period } t, E \text { is the average earning for the last four quarters. * Only positive indicator values are } \\
\text { included. The sample period is from } 1995 \text { to } 2012,64 \text { Quarters. Source: my own research. }\end{array}$} \\
\hline
\end{tabular}


The average values of $M V / E, M V / B V$ indicators, and average returns on joined quaintile portfolios for all modes are similar. However, $R O E$ assumes higher values and less-standard deviations if speculative stocks MS2 are eliminated.

Figure 1 shows the distributions of $R O E$ indicator for joined quaintiles forming in M1, MS1 and MS2 modes.

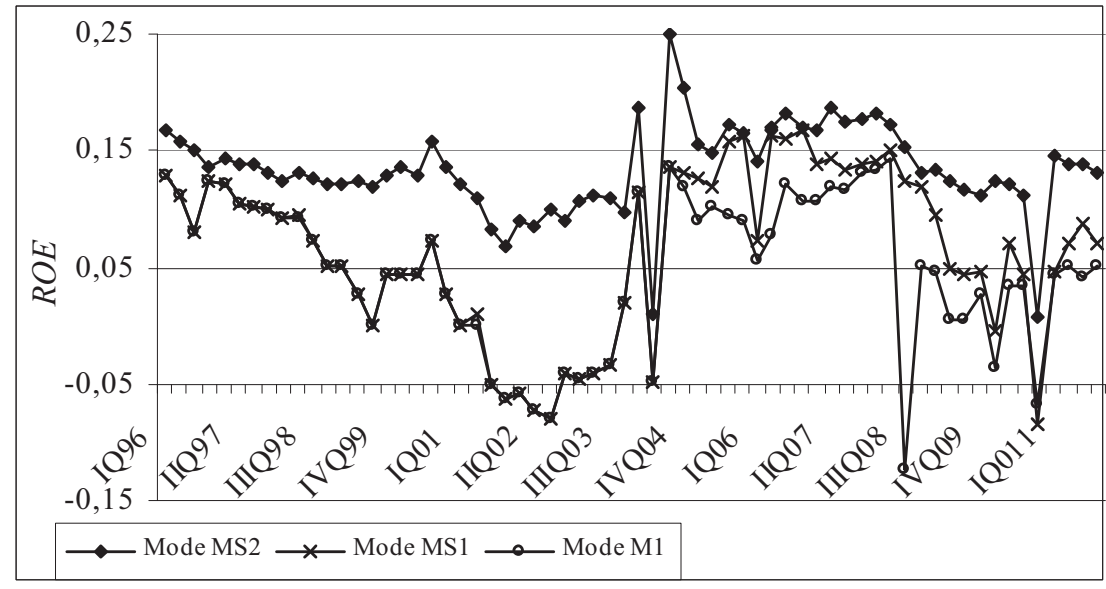

Figure 1. Changes of $R O E$ indicator of positive book value stock portfolios

Notes: In M1, negative- $B V$ stocks are excluded from the portfolios. Mode MS1 eliminates speculative stocks that meet one of the following boundary conditions: a) $B V<0$ and $M V / B V>100$; b) $B V<0$ and $R O E<0$ and $r_{i t}>0$; c) $B V<0$ and $M V / B V>30$ and $r_{i t}>0$. Mode MS2 eliminates speculative stocks that meet additional condition d) $M V / E<0$, where $M V$ is a market value of stock (portfolio), $R O E$ is the return on book value $(B V), r_{i t}$ is the return of portfolio $i$ in period $t, E$ is the average earning for the last four quarters. The values of $R O E$ indicator for portfolio are determined as an arithmetic mean of $R O E$ for stocks included in the portfolio. Source: my own research.

\section{Stock pricing in light of the ICAPM}

The statistical model testing the ICAPM can be described by equations (4) and (5). The regressions of time series (4) are analyzed in the first pass. Equation (5) is analyzed in the second pass as cross-section regressions $(\forall t=1, \ldots, \mathrm{T}$; Fama-MacBeth (1973) procedure is used) and the time-cross-section regression, using panel data.

$$
r_{i t}-R F_{t}=\alpha_{i}+\sum_{k=1}^{K} \beta_{i k} F_{k t}+e_{i t} ; t=1, \ldots, T ; \forall i=1, \ldots, m
$$


The impact of speculation on the pricing of companies...

$$
r_{i t}-R F_{t}=\gamma_{0}+\sum_{k=1}^{K} \gamma_{k} \hat{\beta}_{i k}+\varepsilon_{i t} ; i=1, \ldots, m ; t=1, \ldots, T
$$

where $T$ is the number of analyzed periods, $m$ is the number of portfolios, $F_{k t}$ constitutes the value of $\boldsymbol{k}$-th explanatory variable in period $t$.

The response variable is seen as an excess over the risk-free rate $(R F)$ in the tested portfolios. The explanatory variables for portfolio $i$ and period $t$ define Equations (6) and (7):

$$
\begin{gathered}
x_{1 i t}=R M O A_{t} ; x_{2 i t}=H_{M L N} ; x_{3 i t}=L M H D_{t} \\
x_{4 i t}=R M O F_{t} ; x_{5 i t}=H M L_{t} ; x_{6 i t}=S M B_{t}
\end{gathered}
$$

where the $H M L_{t}$ and $S M B_{t}$ are FF factors; $H M L N_{t}$ (high minus low) is the difference between the returns from the portfolio with the highest and lowest $N U M_{t}$ values in period $t ; L M H D_{t}$ (low minus high) is the difference between the returns from the portfolio with the lowest and highest $D E N_{t}$ values in period $t ; R M O A_{t}$ is the market factor, defined as excess market return over the risk-free rate, not correlated with $H M L N_{t}$ and $L M H D_{t}$; and $R M O F_{t}$ is the market factor, defined as excess market return over the risk-free rate, not correlated with $H M L_{t}$ and $S M B_{t}$. The market return $(R M)$ is evaluated by the return on the WIG index of the Warsaw Stock Exchange. $R F$ is evaluated by a 91-day Polish Treasury bill return observed at the beginning of the tested period.

The response variable and explanatory variables are subject to stationarity tests whose hypothesis is based on the Dickey-Fuller and Phillips-Perron tests. Dickey-Fuller and Phillips-Perron tests confirm a lack of unit elements for each test case. Augmented Dickey-Fuller tests carried out for lag, defined on the basis of minimizing the modified Akaike criterion, indicate a lack of unit elements in the most of the tested cases $^{2}$. The present research leads to conclusions about the stationarity of the analyzed variables.

The values of parameters of regressions (4) and (5) are determined by means of the GLS method with the application of the Prais-Winsten procedure with firstorder autocorrelation. The impact of heteroskedasticity is taken into account by means of the change of variables method ${ }^{3}$. The impact of estimation errors of the true beta values in the first pass is taken into account by correcting the standard errors of beta loadings (estimated in the second pass), using Shanken's estimator (see Shanken, 1992).

2 Test findings are available from the author by request.

3 The covariance matrix of regression coefficients is also estimated using the Newey-West estimator where standard errors are corrected for autocorrelation and heteroskedasticity. The results are qualitatively similar. They are available upon request. 


\subsection{The pricing simulation by aggregated three-factor model}

The response variable of the regressions (4) and (5) constitutes the excess of $R F$ on 15 portfolios constructed on $F U N, N U M$, and $D E N$ values. Explanatory variables of regression (4) are $F_{1 t} \equiv R M O A_{t}, F_{2 t} \equiv H M L N_{t}$ and $F_{3 t} \equiv L M H D_{t}$ factors defined by relationship (6). Explanatory variables of regression (5) are betas estimated in the first pass.

Table 3 presents the values of parameters of regression (4) and the GRS-F statistics indicating that the intercepts of regression (4) are jointly equal to zero (see Gibbons et al., 1989).

Table 3

Time-series regression of excess stock returns on the orthogonalized stock-market factor, $R M O 2$, and the mimicking returns for the $N U M$ value, $H M L N$, and for $D E N$ value, $L M H D$, factors $r_{i t}-R F_{t}=\alpha_{i}+\beta_{i, M O A} R M O A_{t}+\beta_{i, H M L N} H M L N_{t}+\beta_{i, L M H D} L M H D_{t}+e_{i t}$, $t=1, \ldots, 64 ; \forall i=1, \ldots, 15$

\begin{tabular}{|c|c|c|c|c|c|c|c|c|}
\hline \multicolumn{9}{|c|}{$\begin{array}{l}\text { Response variable: excess returns on } 15 \text { stock portfolios formed on } F U N, N U M \text { and } D E N \\
\text { Mode M1: GRS- } F=1.89, p \text {-value }(\text { GRS })=0.05 ; \mathrm{R}^{2}=74-90 \% . \\
\text { Mode MS1: GRS- } F=2.78, p \text {-value }(\text { GRS })=0.01 ; \mathrm{R}^{2}=73-89 \% . \\
\text { Mode MS2: GRS- } F=1.21, p \text {-value }(\mathrm{GRS})=0.30 ; \mathrm{R}^{2}=68-85 \% .\end{array}$} \\
\hline Quaintile & $\alpha_{i}$ & $p$-value & $\beta_{i, M O A}$ & $p$-value & $\beta_{i, H M L N}$ & $p$-value & $\beta_{i, \text { LMHD }}$ & $p$-value \\
\hline \multicolumn{9}{|c|}{ Mode M1; Portfolios formed on $F U N$} \\
\hline MIN & -0.01 & 0.69 & 1.12 & 0.00 & -0.40 & 0.00 & -0.57 & 0.00 \\
\hline 2 & -0.02 & 0.05 & 0.90 & 0.00 & -0.20 & 0.09 & -0.39 & 0.00 \\
\hline 3 & -0.02 & 0.05 & 0.81 & 0.00 & 0.32 & 0.00 & -0.32 & 0.00 \\
\hline 4 & -0.02 & 0.05 & 0.97 & 0.00 & 0.42 & 0.00 & -0.15 & 0.03 \\
\hline MAX & 0.02 & 0.04 & 1.01 & 0.00 & 0.45 & 0.00 & -0.31 & 0.00 \\
\hline \multicolumn{9}{|c|}{ Mode M1; Portfolios formed on NUM } \\
\hline MIN & 0.01 & 0.55 & 1.15 & 0.00 & -0.54 & 0.00 & -0.47 & 0.00 \\
\hline 2 & -0.01 & 0.38 & 0.89 & 0.00 & -0.45 & 0.00 & -0.21 & 0.05 \\
\hline 3 & -0.02 & 0.03 & 0.76 & 0.00 & 0.17 & 0.07 & -0.19 & 0.14 \\
\hline 4 & -0.01 & 0.12 & 1.05 & 0.00 & 0.46 & 0.00 & -0.28 & 0.00 \\
\hline MAX & 0.01 & 0.37 & 0.99 & 0.00 & 0.53 & 0.00 & -0.39 & 0.00 \\
\hline
\end{tabular}


The impact of speculation on the pricing of companies...

Table 3 cont.

\begin{tabular}{|c|c|c|c|c|c|c|c|c|}
\hline \multicolumn{9}{|c|}{ Mode M1; Portfolios formed on $D E N$} \\
\hline MIN & 0.02 & 0.02 & 0.97 & 0.00 & 0.07 & 0.45 & 0.19 & 0.02 \\
\hline 2 & -0.02 & 0.07 & 1.07 & 0.00 & 0.20 & 0.02 & 0.19 & 0.01 \\
\hline 3 & -0.02 & 0.02 & 0.87 & 0.00 & 0.28 & 0.00 & -0.17 & 0.04 \\
\hline 4 & 0.00 & 0.97 & 0.88 & 0.00 & 0.24 & 0.01 & -0.75 & 0.00 \\
\hline MAX & 0.01 & 0.64 & 1.12 & 0.00 & 0.06 & 0.57 & -0.88 & 0.00 \\
\hline \multicolumn{9}{|c|}{$\begin{array}{l}\text { Notes: } R F \text { is the 91-day Treasury bill rate of return. Factors } H M L N, L M H D \text {, and } R M O A \text { are defined } \\
\text { by equation (6). GRS- } F \text { is the } F \text {-statistics of Gibbons et al. (1989). The Prais-Winsten algorithm is } \\
\text { used for correction of autocorrelation. In M1, negative- } B V \text { stocks are excluded from the portfolios. } \\
\text { Mode MS1 eliminates speculative stocks that meet one of the following boundary conditions: } \\
\left.\text { a) } B V<0 \text { and } M V / B V>100 ; \text { b) } B V<0 \text { and } R O E<0 \text { and } r_{i t}>0 \text {; }\right) B V<0 \text { and } M V / B V>30 \text { and } \\
r_{i t}>0 \text {. Mode MS2 eliminates speculative stocks that meet additional condition d) } M V / E<0 \text {, where } \\
M V \text { is a market value of stock (portfolio), } R O E \text { is the return on book value }(B V), r_{i t} \text { is the return of } \\
\text { portfolio } i \text { in period } t, E \text { is the average earning for the last four quarters. The sample period is from } \\
1995 \text { to } 2012,64 \text { Quarters. Source: my own research. }\end{array}$} \\
\hline
\end{tabular}

Beta values are estimators of systematic risk connected with the factors. The betas are significantly different from zero for most of the tested cases. The beta values for market portfolio factor are similar for different modes of portfolio building. However, betas connected with $H M L N$ and $L M H D$ are shifted toward positive values of about $20 \%$ and $200 \%$, respectively, for MS1 and MS2 modes. The betas connected with HMLN change as follows: from -0.40 to 0.63 for FUN portfolios, from -0.65 to 0.67 for $N U M$ and from 0.06 to 0.34 for portfolios formed on $D E N$. The betas connected with $L M H D$ change as follows: from -0.57 to 0.38 for $F U N$ portfolios, from -0.27 to 0.33 for $N U M$ and from -0.88 to 1.06 for portfolios formed on $D E N$.

Coefficient $R^{2}$ seems to be independent of portfolio forming and ranges from 73 to $90 \%$.

If speculative stocks are eliminated, the intercepts of regressions (4) are equal to zero for all portfolios formed on FUN, NUM, and DEN. This is confirmed by the GRS- $F$ statistics equal to: 1.89 ( $p$-value $=0.05$ ) for mode M1 and 1.21 $(p$-value $=0.30)$ for mode MS2. This proves that the aggregated three-factor model generates multifactor-efficient portfolios for MS2 mode. It is in line with Conjecture 1. 
In the second pass, risk prices for the factors are estimated. The risk prices are defined by beta loadings of regression (5). Table 4 presents the values of estimated parameters of regressions (5), the values of informal determination coefficient $R_{L L}^{2}$ applied by Lettau and Ludvigson (2001), and the values of $Q^{A}(F)$ statistics $^{4}$.

\section{Table 4}

The values of the risk premium vector $(\gamma)$ estimated from second-pass regressions for the aggregated three-factor model

\begin{tabular}{|c|c|c|c|c|c|c|}
\hline & \multicolumn{3}{|c|}{$\begin{array}{l}\text { Pooled time series and time- } \\
\text { cross-sectional estimation }\end{array}$} & \multicolumn{3}{|c|}{ Fama-MacBeth estimation } \\
\hline & M1 & MS1 & MS2 & M1 & MS1 & MS2 \\
\hline$\gamma_{0}$ & -0.07 & -0.09 & -0.05 & -0.11 & -0.09 & -0.07 \\
\hline$p$-value & 0.08 & 0.13 & 0.61 & 0.02 & 0.11 & 0.22 \\
\hline$p$-value ${ }^{s}$ & 0.17 & 0.28 & 0.68 & 0.08 & 0.25 & 0.33 \\
\hline$\gamma_{H M L N}$ & 0.05 & 0.06 & 0.05 & 0.05 & 0.06 & 0.05 \\
\hline$p$-value & 0.00 & 0.00 & 0.00 & 0.01 & 0.00 & 0.01 \\
\hline$p$-value ${ }^{s}$ & 0.01 & 0.00 & 0.01 & 0.02 & 0.00 & 0.02 \\
\hline$\gamma_{M O A}$ & 0.06 & 0.07 & 0.02 & 0.10 & 0.07 & 0.04 \\
\hline$p$-value & 0.16 & 0.28 & 0.88 & 0.05 & 0.28 & 0.58 \\
\hline$p$-value* & 0.25 & 0.44 & 0.90 & 0.14 & 0.44 & 0.65 \\
\hline$\gamma_{L M H M}$ & 0.04 & 0.06 & 0.06 & 0.04 & 0.06 & 0.05 \\
\hline$p$-value & 0.04 & 0.00 & 0.00 & 0.05 & 0.00 & 0.00 \\
\hline$p$-value* & 0.07 & 0.01 & 0.01 & 0.10 & 0.01 & 0.01 \\
\hline
\end{tabular}

${ }^{4} R_{L L}^{2}$ is a measure showing the fraction of the cross-sectional variation in average returns that is explained by a tested model and is calculated as follows: $R_{L L}^{2}=\left[\sigma_{c}^{2}\left(\overline{r_{i}}\right)-\sigma_{c}^{2}\left(\overline{e_{i}}\right)\right] / \sigma_{c}^{2}\left(\overline{r_{i}}\right)$, where $\sigma_{c}^{2}$ denotes a cross-sectional variance, and variables with bars over them denote time-series averages. $Q^{A}(F)$ reports $F$-statistic for the test of Shanken (1985) that the pricing errors in the model are jointly equal to zero. A pricing model genarates multifactor-efficient portfolios if the pricing errors or intercepts in the model are jointly equal to zero. 
The impact of speculation on the pricing of companies...

Table 4 cont.

\begin{tabular}{|c|r|r|r|r|r|r|}
\hline$R_{L L}^{2}, \%$ & 73.75 & 78.05 & 86.15 & 72.75 & 78.27 & 85.47 \\
\hline$Q^{A}(F)$ & 2.21 & 2.42 & 1.46 & 2.21 & 2.42 & 1.46 \\
$(p$-value $)$ & $(0.02)$ & $(0.02)$ & $(0.18)$ & $(0.02)$ & $(0.02)$ & $(0.18)$ \\
\hline
\end{tabular}

Notes: In M1, negative- $B V$ stocks are excluded from the portfolios. Mode MS1 eliminates speculative stocks that meet one of the following boundary conditions: a) $B V<0$ and $M V / B V>100$; b) $B V<0$ and $R O E<0$ and $r_{i t}>0$; c) $B V<0$ and $M V / B V>30$ and $r_{i t}>0$. Mode MS2 eliminates speculative stocks that meet additional condition d) $M V / E<0$, where $M V$ is a market value of stock (portfolio), $R O E$ is the return on book value $(B V), r_{i t}$ is the return of portfolio $i$ in period $t, E$ is the average earning for the last four quarters. $R F$ is the 91-day Polish Treasury bill return. $\hat{\beta}_{i, M O A}$ is the loading on the orthogonalized market factor estimated from first-pass time-series regressions. $\hat{\beta}_{i, H M L N}$ and $\hat{\beta}_{i, H M L N}$ are loadings on $H M L N$ and $L M H D$ estimated from first-pass timeseries regressions. $R_{L L}^{2}$ is a measure, follows Lettau and Ludvigson (2001), showing the fraction of the cross-sectional variation in average returns that is explained by each model. $Q^{4}(F)$ reports $F$-statistics and its corresponding $p$-value (indicated below in brackets) for the test of Shanken (1985) that the pricing errors in the model are jointly zero. The response variable is excess return on 15 stock portfolios formed on FUN, NUM, and DEN. The Prais-Winsten algorithm is used for correction of autocorrelation. * After adjusting for errors-in-variables, according to Shanken (1992). The sample period is from 1995 to 2012, 64 Quarters. Source: my own research.

The values of risk prices $\gamma_{H M L N}$ and $\gamma_{L M H D}$ are significantly different from zero in both estimations and the three tested modes: M1, MS1, and MS2 ( $p$-values $<0.07$, after correction of error in variables). Risk price $\gamma_{M O A}$ is insignificantly different from zero, which does not contradict the ICAPM assumptions (see Fama, 1996, pp. 456 and 463-464). Estimated risk prices seemingly indicate that speculative stocks do not affect the portfolio pricing.

However, note the increase in $R_{L L}^{2}$ if speculative stocks are eliminated from the portfolios. The coefficient $R_{L L}^{2}$ grows from $73.75 \%$ for M1 to $78.05 \%$ and 86.15\% for MS1 and MS2. It is in line with Conjecture 2.

Also, the results of intercept estimation of second pass confirm the pricing correctness in light of the ICAPM for MS1 and MS2 modes. The intercepts $\gamma_{0}$ assume values $-0.07,-0.09$ and -0.05 with corresponding $p$-values $0.08,0.13$ and 0.61 , respectively $(0.17,0.28$ and 0.68 , after error in variables adjusting). It is in line with Conjecture 1.

Additionally, pricing errors decrease after elimination of speculative stocks. It is documented by values of $Q^{A}(F)$ statistics: 2.21 for M1 and 1.46 for MS2, with the corresponding $p$-values 0.02 and 0.18 , respectively. This confirms the results of the GRS test (from the first pass) that the aggregated three-factor model generates multifactor-efficient portfolios if speculative stocks (according to MS2 mode) are eliminated. Also, lower pricing errors indicate that the simulated expected returns are closer to realized average returns. It is in line with Conjectures 1 and 2. 
a) b)

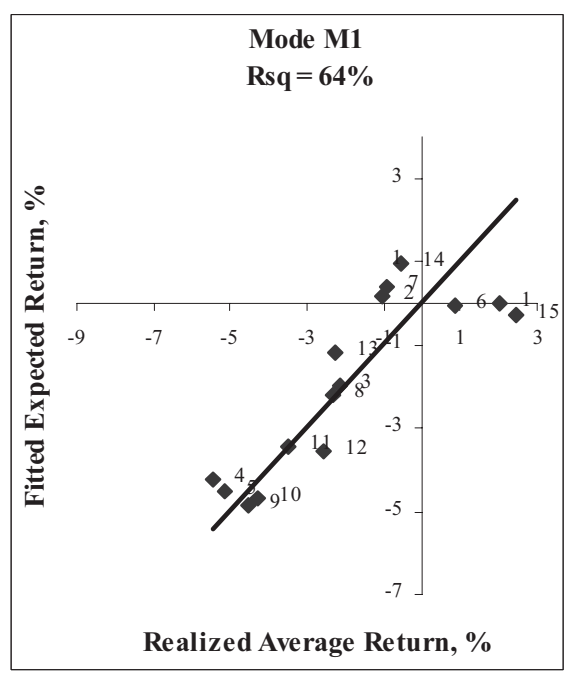

c)

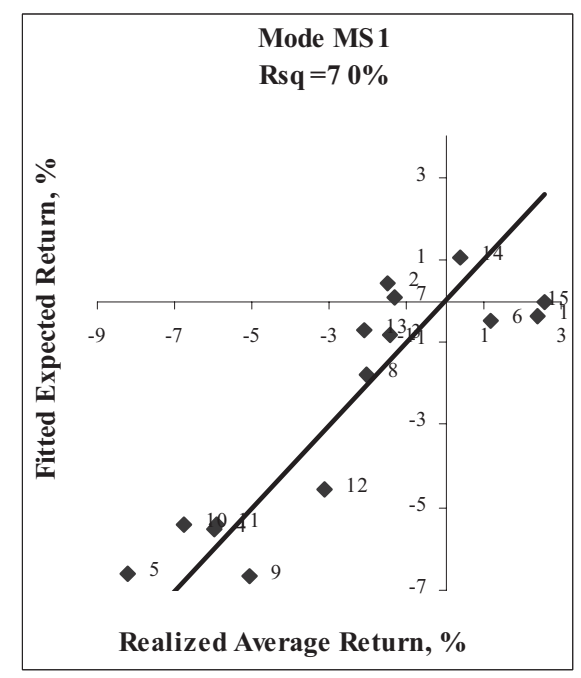

Figure 2. Fitted expected returns, simulated by the agregated three-factor model, versus realized average returns: a) Mode M1 negative- $B V$ stocks are excluded from the portfolios; b) Mode MS1 eliminates speculative stocks that meet one of the following boundary conditions: 1) $B V<0$ and $M V / B V>100,2) B V<0$ and $R O E<0$ and $\left.r_{i t}>0,3\right) B V<0$ and $M V / B V>30$ and $r_{i t}>0$; c) Mode MS2 eliminates speculative stocks that meet additional condition 4) $M V / E<0$, where $M V$ is a market value of stock, $R O E$ is the return on book value $(B V), r_{i t}$ is the return of portfolio $i$ in period $t, E$ is the average earning for the last four quarters. The figure shows the pricing errors for each of the 15 portfolios. Each number of scatter points represents one portfolio, 1-5 portfolios formed on FUN, 6-10 portfolios formed on NUM, and 11-15 portfolios are formed on DEN. For each portfolio $i$, the realized average return is the time-series average of the portfolio return and the fitted expected return is the value for the expected return, $\mathrm{E}\left[r_{i}\right]$, in the following regression model: $E\left[r_{i}\right]=\gamma_{0}+\sum_{l=1}^{L} \gamma_{l} \beta_{i l}$, where $\beta_{i l}$ are the slope coefficients in the first-pass GLS regression of the returns' excess of the portfolios in respect of the used factors, $\gamma_{0}$ is the expected return on a "zero-beta" portfolio, $\gamma_{l}$ is the $l$ component of risk premium vector, $\gamma_{0}$ and $\gamma_{l}$ are estimated from a second-pass GLS regression. If the model fits perfectly, all of the points would lie along the 45 -degree line. Rsq is the $R^{2}$ coefficient on condition that the simple regression does not contain an intercept and is inclined towards the abscissa of a point at an angle of 45 degrees. Source: my own research. 
The impact of speculation on the pricing of companies...

The visual assessment (applied by Jagannathan and Wang [1996]) of the influence of speculative stocks on pricing errors is shown in Figure 2. This figure presents pricing errors in each of the tested portfolios, marked with numbers 1 to 15 . Portfolios 1 to 5 are formed on FUN values, from 6 to 10 on $N U M$ values, and from 11 to 15 on $D E N$ values. After exclusion of speculative stocks from analysis, the Rsq coefficient increases, assuming $64 \%$ for mode M1, 70\% for mode MS1, and $85 \%$ for mode MS25. These results also confirm that the elimination of speculative stocks reduces pricing errors and "improves" the fitted expected returns, simulated by the aggregated three-factor model. It is in line with Conjecture 2 .

\subsection{The pricing simulation by Fama-French model}

The response variable of regressions (4) and (5) constitutes the excess of $R F$ on ten portfolios constructed on $B V / M V$ and $C A P$ values. Explanatory variables of regression (4) are $F_{1 t} \equiv R M O F_{t}, F_{2 t} \equiv H M L_{t}$ and $F_{3 t} \equiv S M B_{t}$ factors defined by relationship (7). Explanatory variables of regression (5) are betas estimated in the first pass.

Table 5 presents the values of parameters of regression (4) and the GRS-F statistics.

\section{Table 5}

Time-series regression of excess stock returns on the orthogonalized stock-market factor, $R M O F$, and the mimicking returns for the $B V / M V$ value, $H M L$, and for $C A P$ value, $S M B$, factors $r_{i t}-R F_{t}=\alpha_{i}+\beta_{i, M O F} R M O F_{t}+\beta_{i, H M L} H M L_{t}+\beta_{i, S M B} S M B_{t}+e_{i t}, t=1, \ldots, 64 ; \forall i=1, \ldots, 10$

\begin{tabular}{|c|c|c|c|c|c|c|c|c|}
\hline \multicolumn{9}{|c|}{$\begin{array}{l}\text { Response variable: excess returns on } 10 \text { stock portfolios formed on } B V / M V \text { and } C A P \\
\text { Mode M1: GRS- } F=1.27, p \text {-value }(\mathrm{GRS})=0.27 ; R^{2}=65-95 \% \\
\text { Mode MS1: GRS- } F=2.25, p \text {-value }(\mathrm{GRS})=0.03 ; R^{2}=72-95 \% \\
\text { Mode MS2: GRS- } F=1.88, p \text {-value }(\mathrm{GRS})=0.07 ; R^{2}=41-95 \%\end{array}$} \\
\hline Quaintile & $\alpha_{i}$ & $\underset{\%}{p \text {-value }}$, & $\beta_{i, \text { MOF }}$ & $\underset{\%}{p \text {-value, }}$, & $\beta_{i, H M L}$ & $\underset{\%}{p \text {-value, }}$, & $\beta_{i, \text { SMB }}$ & $\underset{\%}{p \text {-value, }}$, \\
\hline \multicolumn{9}{|c|}{ Mode M1; Portfolios formed on $B V / M V$} \\
\hline MIN & -0.02 & 0.01 & 0.98 & 0.00 & -0.39 & 0.00 & 0.21 & 0.00 \\
\hline 2 & -0.00 & 0.71 & 0.90 & 0.00 & -0.49 & 0.00 & 0.29 & 0.00 \\
\hline 3 & 0.01 & 0.30 & 1.09 & 0.00 & -0.23 & 0.01 & 0.25 & 0.01 \\
\hline
\end{tabular}

5 Rsq is the $R^{2}$ coefficient on condition that the simple regression does not contain an intercept and is inclined towards the abscissa of a point at an angle of 45 degrees. 
Table 5 cont.

\begin{tabular}{|c|c|r|r|r|r|r|r|r|}
\hline Quaintile & $\alpha_{i}$ & $\begin{array}{c}p \text {-value, } \\
\%\end{array}$ & $\beta_{i, M O F}$ & $\begin{array}{r}p \text {-value, } \\
\%\end{array}$ & $\beta_{i, H M L}$ & $\begin{array}{r}p \text {-value, } \\
\%\end{array}$ & $\beta_{i, S M B}$ & $\begin{array}{c}p \text {-value, } \\
\%\end{array}$ \\
\hline 4 & -0.01 & 0.36 & 0.88 & 0.00 & 0.44 & 0.00 & -0.15 & 0.23 \\
\hline MAX & -0.01 & 0.42 & 0.98 & 0.00 & 0.68 & 0.00 & 0.64 & 0.00 \\
\hline MIN & 0.00 & 0.69 & 1.10 & 0.00 & -0.54 & 0.00 & 1.57 & 0.00 \\
\hline 2 & -0.02 & 0.07 & 0.98 & 0.00 & 0.05 & 0.45 & 1.07 & 0.00 \\
\hline 3 & 0.00 & 0.66 & 1.08 & 0.00 & -0.37 & 0.00 & 0.78 & 0.00 \\
\hline 4 & -0.01 & 0.10 & 1.09 & 0.00 & -0.22 & 0.00 & 0.60 & 0.00 \\
\hline
\end{tabular}

The betas are significantly different from zero for most of the tested cases.

The beta values for market portfolio and $H M L$ factors are similar for different modes of portfolio building. However, betas connected with SMB are shifted toward negative values about $28 \%$ and $45 \%$, respectively, for MS1 and MS2 modes. The betas connected with $H M L$ change as follows: from -0.49 to 0.78 for $B V / M V$ portfolios and from -0.54 to 0.16 for portfolios formed on $C A P$. The betas connected with $S M B$ change as follows: from 0.08 to 0.64 for $B V / M V$ portfolios and from -0.07 to 1.57 for portfolios formed on $C A P$.

Coefficients $\mathrm{R}^{2}$ seem to be independent of portfolio forming, and range from 41 to $95 \%$.

If speculative stocks are eliminated, the intercepts of regressions (4) are different from zero for all portfolios formed on $B V / M V$ and $C A P$. This is confirmed by the GRS- $F$ statistics equal to: $2.25(p$-value $=0.03)$ for MS1 and 1.88 $(p$-value $=0.07)$ for MS2 .

Table 6 presents the values of estimated parameters of regressions (5) as well as the values of $R_{L L}^{2}$ and $Q^{A}(F)$ statistics. 
The impact of speculation on the pricing of companies...

Table 6

The values of the risk premium vector $(\gamma)$ estimated from second-pass regressions for the FF model $r_{i t}-R F_{t}=\gamma_{0}+\gamma_{M O F} \hat{\beta}_{i, M O F}+\lambda_{H M L} \hat{\beta}_{i, H M L}+\lambda_{S M B} \hat{\beta}_{i, S M B}+\varepsilon_{i t} ; i=1, \ldots, 10 ; t=1, \ldots, 64$

\begin{tabular}{|c|c|c|c|c|c|c|}
\hline & \multicolumn{3}{|c|}{$\begin{array}{l}\text { Pooled time series and time- } \\
\text {-cross-sectional estimation }\end{array}$} & \multicolumn{3}{|c|}{ Fama-MacBeth estimation } \\
\hline & M1 & MS1 & MS2 & M1 & MS1 & MS2 \\
\hline$\gamma_{0}$ & -0.05 & -0.05 & 0.03 & -0.05 & -0.06 & 0.00 \\
\hline$p$-value & 0.61 & 0.65 & 0.89 & 0.37 & 0.26 & 0.97 \\
\hline$p$-value* & 0.64 & 0.66 & 0.89 & 0.39 & 0.29 & 0.97 \\
\hline$\gamma_{H M L}$ & 0.03 & 0.02 & 0.03 & 0.02 & 0.02 & 0.03 \\
\hline$p$-value & 0.19 & 0.32 & 0.17 & 0.15 & 0.17 & 0.04 \\
\hline$p$-value* & 0.20 & 0.33 & 0.20 & 0.15 & 0.17 & 0.04 \\
\hline$\gamma_{M O F}$ & 0.05 & 0.04 & -0.03 & 0.04 & 0.04 & -0.01 \\
\hline$p$-value & 0.67 & 0.74 & 0.87 & 0.47 & 0.40 & 0.93 \\
\hline$p$-value* & 0.69 & 0.75 & 0.88 & 0.49 & 0.43 & 0.93 \\
\hline$\gamma_{S M B}$ & 0.01 & 0.00 & 0.01 & 0.01 & 0.00 & 0.01 \\
\hline$p$-value & 0.73 & 0.82 & 0.60 & 0.61 & 0.82 & 0.39 \\
\hline$p$-value* & 0.74 & 0.82 & 0.61 & 0.61 & 0.82 & 0.39 \\
\hline$R_{L L}^{2}, \%$ & 61.32 & 38.11 & 48.25 & 60.70 & 37.91 & 44.75 \\
\hline $\begin{array}{c}Q^{A}(F) \\
(p \text {-value })\end{array}$ & $\begin{array}{r}1.26 \\
(0.29)\end{array}$ & $\begin{array}{r}0.97 \\
(0.45)\end{array}$ & $\begin{array}{r}1.32 \\
(0.26)\end{array}$ & $\begin{array}{r}1.26 \\
(0.29)\end{array}$ & $\begin{array}{r}0.97 \\
(0.45)\end{array}$ & $\begin{array}{r}1.32 \\
(0.26)\end{array}$ \\
\hline \multicolumn{7}{|c|}{$\begin{array}{l}\text { Notes: In M1, negative- } B V \text { stocks are excluded from the portfolios. Mode MS1 eliminates speculative } \\
\text { stocks that meet one of the following boundary conditions: a) } B V<0 \text { and } M V / B V>100 \text {; b) } B V<0 \\
\left.\text { and } R O E<0 \text { and } r_{i t}>0 \text {; }\right) B V<0 \text { and } M V / B V>30 \text { and } r_{i t}>0 \text {. Mode MS2 eliminates speculative } \\
\text { stocks that meet additional condition d) } M V / E<0 \text {, where } M V \text { is a market value of stock (portfolio), } \\
R O E \text { is the return on book value }(B V), r_{i t} \text { is the return of portfolio } i \text { in period } t, E \text { is the average } \\
\text { earning for the last four quarters. } R F \text { is the } 91 \text {-day Polish Treasury bill return. } \hat{\beta}_{i, M O F} \text { is the loading } \\
\text { on the orthogonalized market factor estimated from first-pass time-series regressions. } \hat{\beta}_{i, H M L} \text { and } \\
\hat{\beta}_{i, S M B} \text { are loadings on Fama-French factors, estimated from first-pass time-series regressions. } R_{L L}^{2} \\
\text { is a measure, follows Lettau and Ludvigson }(2001) \text {, showing the fraction of the cross-sectional } \\
\text { variation in average returns that is explained by each model. } Q^{4}(F) \text { reports } F \text {-statistics and its } \\
\text { corresponding } p \text {-value (indicated below in brackets) for the test of Shanken (1985) that the } \\
\text { pricing errors in the model are jointly zero. The response variable is excess return on } 15 \text { stock } \\
\text { portfolios formed on } F U N, N U M \text { and } D E N \text {. The Prais-Winsten algorithm is used for correction of } \\
\text { autocorrelation. * After adjusting for errors-in-variables, according to Shanken (1992). The sample } \\
\text { period is from } 1995 \text { to } 2012,64 \text { Quarters. Source: my own research. }\end{array}$} \\
\hline
\end{tabular}


The values of all risk prices: $\gamma_{H M L}, \gamma_{S M B}$, and $\gamma_{M O F}$ are insignificantly different from zero in time-cross-sectional estimation and the three tested modes: M1, MS1, and MS2 ( $p$-values $>0.20$, after correction of error in variables $)^{6}$. This means that the FF model does not allow for pricing the stocks listed on WSE, in light of the ICAPM, and speculation stocks do not affect the estimation result ${ }^{7}$. It is in line with Conjecture 3.

\section{The impact of characteristics of formed portfolios on ICAPM specifications}

Jagannathan and Wang (1998) claim that considering a characteristic of formed portfolios is advisable in testing the ICAPM applications, while Urbański (2011) shows the predictive possibilities of FUN, NUM, and DEN, on the basis of which quaintile portfolios are formed. For this reason, I verify the validity of the aggregated three-factor ICAPM application in the presence of characteristics of built portfolios. The general form of the test is shown by equation (8):

$$
\begin{gathered}
r_{i t}-R F_{t}=\gamma_{0}+\gamma_{H M L N} \hat{\beta}_{i, H M L N}+\gamma_{M O A} \hat{\beta}_{i, M O A}+\gamma_{L M H M} \hat{\beta}_{i, L M H M}+\gamma_{Z} Z_{i, t-1}+\varepsilon_{i t} \\
i=1, \ldots, 15 ; t=1, \ldots, 63
\end{gathered}
$$

where $Z_{i, t-1}$ are $F U N_{i}, N U M_{i}$, or $D E N_{i}$ for period $t-1$, and null hypothesis is $\mathrm{H}_{0}: \gamma_{Z}=0$.

Practically, the following regressions are analyzed:

$$
\begin{aligned}
& r_{i t}-R F_{t}=\gamma_{0}+\gamma_{H M L N} \hat{\beta}_{i, H M L N}+\gamma_{M O A} \hat{\beta}_{i, M O A}+\gamma_{L M H M} \hat{\beta}_{i, L M H M}+\gamma_{Z} F U N_{i, t-1}+\varepsilon_{i t} \\
& r_{i t}-R F_{t}=\gamma_{0}+\gamma_{H M L N} \hat{\beta}_{i, H M L N}+\gamma_{M O A} \hat{\beta}_{i, M O A}+\gamma_{L M H M} \hat{\beta}_{i, L M H M}+\gamma_{Z} N U M_{i, t-1}+\varepsilon_{i t} \\
& r_{i t}-R F_{t}=\gamma_{0}+\gamma_{H M L N} \hat{\beta}_{i, H M L N}+\gamma_{M O A} \hat{\beta}_{i, M O A}+\gamma_{L M H M} \hat{\beta}_{i, L M H M}+\gamma_{Z} D E N_{i, t-1}+\varepsilon_{i t} \\
& r_{i t}-R F_{t}=\gamma_{0}+\gamma_{H M L N} \hat{\beta}_{i, H M L N}+\gamma_{M O A} \hat{\beta}_{i, M O A}+\gamma_{L M H M} \hat{\beta}_{i, L M H M}+\gamma_{Z} F N D_{i, t-1}+\varepsilon_{i t}
\end{aligned}
$$

In regression (7) $F U N_{i, t-1}$ is a vector with coordinates: $\mathrm{FUN}_{1, t-1}, \ldots, F U N_{5, t-1}$, $F U N_{1, t-1}, \ldots, F U N_{5, t-1}, F U N_{1, t-1}, \ldots, F U N_{5, t-1}$. Similarly, in regressions (10-12) $N U M_{i, t-1}$ is a vector: $N U M_{1, t-1}, \ldots, N U M_{5, t-1}, N U M_{1, t-1}, \ldots, N U M_{5, t-1}, N U M_{1, t-1}, \ldots, N U M_{5, t-1}$.

${ }^{6}$ Only $\gamma_{\text {нмL }}$ is greater than zero in Fama-MacBeth estimation and MS2 mode.

7 An ICAPM application should generate significantly different from zero systematic risk and risk prices components, as well as multifactor-efficient portfolios. Used FF application, due to the small return spreads for portfolios formed on $B V / M V$ and $C A P$ (on WSE), generates insignificant risk prices. 
The impact of speculation on the pricing of companies...

$D E N_{i, t-1}$ is a vector: $D E N_{1, t-1}, \ldots, D E N_{5, t-1}, D E N_{1, t-1}, \ldots, D E N_{5, t-1}, D E N_{1, t-1}, \ldots$, $D E N_{5, t-1}$. Variable $F N D_{i, t-1}$ is a vector with coordinates: $F U N_{i, t-1}, i=1, \ldots, 5$, $N U M_{i, t-1}, i=1, \ldots, 5$ and $D E N_{i, t-1}, i=1, \ldots, 5$.

The estimated parameter values of regressions (9-12) are shown in Table 7. Panel A shows whether lagged $F U N$ adds new information into aggregated model. Similarly, panels B, C and D show whether lagged NUM, DEN, and FND, respectively, add new information. Parameter $\gamma_{Z}$ assumes small values, with corresponding $p$-values $>0.08$ if speculative stocks are excluded from analysis. The test results show that lagged $F U N, N U M$, and DEN added into regression separately (see Panels $\mathrm{A}, \mathrm{B}$, and C) or in conjunction (see Panel D) have insignificant influence on estimation results in tested modes: M1, MS1, and MS2.

Table 7

Time-cross-section regressions showing the effect of the portfolio characteristics, representing specification tests of ICAPM for the whole sample $r_{i t}-R F_{t}=\gamma_{0}+$

$+\gamma_{H M L N} \hat{\beta}_{i, H M L N}+\gamma_{M O A} \hat{\beta}_{i, M O A}+\gamma_{L M H M} \hat{\beta}_{i, L M H M}+\gamma_{Z} Z_{i, t-1}+\varepsilon_{i t} ; i=1, \ldots, 15 t=1, \ldots, 63$

\begin{tabular}{|c|c|c|c|c|c|c|c|c|c|}
\hline & \multirow[b]{2}{*}{ Mode } & \multicolumn{2}{|c|}{ Panel A } & \multicolumn{2}{|c|}{ Panel B } & \multicolumn{2}{|c|}{ Panel C } & \multicolumn{2}{|c|}{ Panel D } \\
\hline & & $\begin{array}{l}Z= \\
\boldsymbol{F} U \boldsymbol{N}\end{array}$ & $p$-value & $\begin{array}{c}Z= \\
N U M\end{array}$ & $p$-value & $\begin{array}{c}Z= \\
D E N\end{array}$ & $p$-value & $\begin{array}{c}Z= \\
F N D\end{array}$ & $p$-value \\
\hline \multirow{3}{*}{$\gamma_{o}$} & M1 & -0.07 & 0.08 & -0.07 & 0.08 & -0.06 & 0.16 & -0.08 & 0.08 \\
\hline & MS1 & -0.10 & 0.11 & -0.10 & 0.10 & -0.09 & 0.17 & -0.10 & 0.11 \\
\hline & MS2 & -0.11 & 0.26 & -0.08 & 0.40 & -0.01 & 0.94 & -0.06 & 0.53 \\
\hline \multirow{3}{*}{$\gamma_{H M L N}$} & M1 & 0.04 & 0.06 & 0.04 & 0.05 & 0.02 & 0.44 & 0.04 & 0.07 \\
\hline & MS1 & 0.03 & 0.19 & 0.03 & 0.13 & 0.05 & 0.03 & 0.04 & 0.08 \\
\hline & MS2 & 0.01 & 0.50 & 0.03 & 0.19 & 0.05 & 0.02 & 0.03 & 0.10 \\
\hline \multirow{3}{*}{$\gamma_{M O A}$} & M1 & 0.06 & 0.16 & 0.06 & 0.16 & 0.03 & 0.61 & 0.06 & 0.18 \\
\hline & MS1 & 0.07 & 0.31 & 0.07 & 0.30 & 0.05 & 0.48 & 0.07 & 0.30 \\
\hline & MS2 & 0.05 & 0.60 & 0.03 & 0.74 & -0.01 & 0.92 & 0.02 & 0.87 \\
\hline \multirow{3}{*}{$\gamma_{L M H D}$} & M1 & 0.04 & 0.09 & 0.04 & 0.07 & 0.06 & 0.01 & 0.04 & 0.04 \\
\hline & MS1 & 0.07 & 0.00 & 0.07 & 0.00 & 0.07 & 0.00 & 0.06 & 0.00 \\
\hline & MS2 & 0.08 & 0.00 & 0.07 & 0.00 & 0.05 & 0.03 & 0.06 & 0.00 \\
\hline
\end{tabular}


Table 7 cont.

\begin{tabular}{|c|c|c|c|c|c|c|c|c|c|}
\hline & \multirow[b]{2}{*}{ Mode } & \multicolumn{2}{|c|}{ Panel A } & \multicolumn{2}{|c|}{ Panel B } & \multicolumn{2}{|c|}{ Panel C } & \multicolumn{2}{|c|}{ Panel D } \\
\hline & & $\begin{array}{l}Z= \\
F U N\end{array}$ & $p$-value & $\begin{array}{c}Z= \\
N U M\end{array}$ & $p$-value & $\begin{array}{l}Z= \\
D E N\end{array}$ & $p$-value & $\begin{array}{l}Z= \\
F N D\end{array}$ & $p$-value \\
\hline \multirow{3}{*}{$\gamma_{z}$} & M1 & 0.00 & 0.86 & 0.01 & 0.78 & 0.02 & 0.05 & 0.00 & 0.55 \\
\hline & MS1 & 0.01 & 0.13 & 0.01 & 0.15 & 0.01 & 0.28 & 0.01 & 0.19 \\
\hline & MS2 & 0.01 & 0.08 & 0.01 & 0.21 & -0.01 & 0.61 & 0.01 & 0.34 \\
\hline
\end{tabular}

Notes: Time-cross-section estimation is applied using panel data. The beta parameters are estimated (in the first pass) by GLS using Prais-Winsten procedure while, heteroskedasticity is corrected (in the second pass) by means of the change of variables method. The table shows whether lagged FUN, NUM, DEN, and $F N D$ add new information into the analyzed ICAPM application. Variable $F N D_{i, t-1}$ is a vector with coordinates: $F U N_{i, t-1}, i=1, \ldots, 5, N U M_{i, t-1}, i=1, \ldots, 5$ and $D E N_{i, t-1}, i=1, \ldots, 5$. In $M 1$, negative- $B V$ stocks are excluded from the portfolios. Mode MS1 eliminates speculative stocks that meet one of the following boundary conditions: a) $B V<0$ and $M V / B V>100$; b) $B V<0$ and $R O E<0$ and $r_{i t}>0$; c) $B V<0$ and $M V / B V>30$ and $r_{i t}>0$. Mode MS2 eliminates speculative stocks that meet additional condition d) $M V / E<0$, where $M V$ is a market value of stock (portfolio), $R O E$ is the return on book value $(B V), r_{i t}$ is the return of portfolio $i$ in period $t, E$ is the average earning for the last four quarters. The sample period is from 1995 to 2012, 64 Quarters. Source: my own research.

\section{Conclusions}

In this paper, I examine the impact of speculative stocks on the simulation results of stock pricing by the chosen ICAPM applications. The performed research, based on Urbański (2012) and FF models, show that the existence of speculation stocks (listed on WSE) and improper procedures for the construction of test portfolios generate a number of inconsistencies with the pricing that could be observed with CAPM validity.

The conducted research leads to the following conclusions:

- If speculative stocks are eliminated, Urbański's model generates multifactor-efficient portfolios. This is confirmed by:

- The intercepts of the regressions in the first pass $\left(\alpha_{i}\right)$ are equal to zero for all portfolios formed on $F U N, N U M$, and DEN. This is confirmed by values of GRS-F statistics, equal to: $1.89(p$-value $=0.05)$ for mode M1, and 1.21 $(p$-value $=0.30)$ for mode MS2 (see Tab. 3$)$.

- The intercepts of regression in the second pass $\left(\gamma_{0}\right)$ are insignificant, assuming values $-0.07,0.09$, and 0.05 with corresponding $p$-values $0.08,0.13$, and 0.61 for M1, MS1, and MS2 modes, respectively (see Tab. 4). 
The impact of speculation on the pricing of companies...

- The pricing errors generated by the model are insignificant. This is confirmed by $Q^{A}(F)$ statistics equal to 1.46 for MS2 mode, with the corresponding $p$-values 0.18 (see Tab. 4 ).

It is in line with Conjecture 1.

- The elimination of speculative stocks "improves" the expected returns fitted by Urbański's model. This is confirmed by:

- The increase in values of cross-sectional determination coefficient $R_{L L}^{2}$ by $17 \%$, from $73.75 \%$ for M1 to $78.05 \%$ and $86.15 \%$ for MS1 and MS2 (see Tab. 4).

- The decrease in pricing errors generated by the model. This is confirmed by:

- the values of $Q^{A}(F)$ statistics: 2.21 for M1 and 1.46 for MS2 modes, with the corresponding $p$-values 0.02 and 0.18 , respectively (see Tab. 4),

- the values of determination coefficient Rsq: $64 \%$ for M1, 70\% for MS1, and $85 \%$ for MS2 modes (see Fig. 2).

It is in line with Conjecture 2.

- The return spreads for portfolios formed on FUN, NUM, and DEN are significantly higher than spreads for portfolios formed on $B V / M V$ and $C A P$. This fact explains the greater usefulness of the aggregated three-factor model as compared to the FF model for stock pricing listed on WSE. This is confirmed by the insignificantly-different-from-zero risk prices $\gamma_{H M L}, \gamma_{S M B}$, and $\gamma_{M O F}$, and speculation stocks do not affect the estimation result. It is in line with Conjecture 3.

- The performed Jagannathan and Wang test shows that characteristics of formed portfolios: lagged $F U N, N U M$, and $D E N$, added to Urbański's application, have insignificant influence on estimation results.

\section{References}

[1] Banz, R.W. (1981) 'The Relationship between Return and Market Value of Common Stock', Journal of Financial Economics, vol. 9 (1), pp. 3-18.

[2] Bołt, T.W. and Miłobędzki, P. (2002) 'Weryfikacja modelu CAPM dla giełdy warszawskiej', Prace Naukowe Akademii Ekonomicznej we Wroclawiu, No 952, pp. 89-95.

[3] Byrka-Kita, K. and Rozkręt, D. (2004) 'Testowanie modelu CAPM na polskim rynku kapitałowym', Zeszyty Naukowe Uniwersytetu Szczecińskiego, No 389 , pp. 307-317.

[4] Cochrane, J. (2001) Asset Pricing, Princeton University Press: Princeton, New Jersey.

[5] Czapkiewicz, A. and Skalna, I. (2010) 'The CAPM and the Fama-French Models in Warsaw Stock Exchange', Przeglad Statystyczny, vol. 57 (4), pp. 128-141. 
[6] De Bondt, W.F.M. and Thaler, R.H. (1985) 'Does the Stock Market Overreact?', Journal of Finance, vol. 40 (3), pp. 793-805.

[7] Fama, E.F. (1996) 'Multifactor Portfolio Efficiency and Multifactor Asset Pricing', Journal of Financial and Quantitative Analysis, vol. 31 (4), pp. 441-465.

[8] Fama, E.F. and MacBeth, J.D. (1973) 'Risk, Return, and Equilibrium: Empirical Tests', Journal of Political Economy, vol. 81 (3), pp. 607-636.

[9] Fama, E.F. and French, K.R. (1993) 'Common Risk Factors in the Returns on Stock and Bonds', Journal of Financial Economics, vol. 33 (1), pp. 3-56.

[10] Fama, E.F. and French, K.R. (1995) 'Size and Book-to-Market Factors in Earnings and Returns', Journal of Finance, vol. 50 (1), pp. 131-155.

[11] Gibbons, M.R., Ross, S.A. and Shanken, J. (1989) 'A Test of the Efficiency of a Given Portfolio', Econometrica, vol. 57 (5), pp. 1121-1152.

[12] Gurgul, H. and Wójtowicz T. (2014) 'The impact of US macroeconomic news on the Polish stock market: the importance of company size to information flow', Central European Journal of Operations Research, vol. 22 (4), pp. 795-817.

[13] Jajuga K. (2000) 'Metody ekonometryczne i statystyczne w analizie rynku kapitałowego', Wydawnictwo Akademii Ekonomicznej: Wrocław.

[14] Jagannathan, R. and Wang, Z. (1996) 'The Conditional CAPM and the CrossSection of Expected Returns', Journal of Finance, vol. 51 (1), pp. 3-53.

[15] Jagannathan, R. and Wang, Z. (1998) Asymptotic Theory for Estimating Beta Pricing Models Using Cross-Sectional Regression', Journal of Finance, vol. 53 (4), pp. 1285-1309.

[16] Jegadeesh, N. and Titman, S. (1993) 'Returns to Buying Winners and Selling Losers: Implications for Stock Market Efficiency', Journal of Finance, vol. 48 (1), pp. 65-91.

[17] Lakonishok, J., Shleifer, A. and Vishny, R.W., 'Contrarian Investment, Extrapolation, and Risk', Journal of Finance, vol. 49 (5), pp. 1541-1578.

[18] Lettau, M. and Ludvigson, S. (2001), 'Resurrecting the (C) CAPM: A Cross-Sectional Test when Risk Premia Are Time-Varying', Journal of Political Economy, vol. 109 (6), pp. 1238-1287.

[19] Osińska, M. and Stępińska, J. (2003) 'Zmienność parametru beta w modelu Sharpe'a a horyzont czasowy inwestycji', Nasz Rynek Kapitałowy, No 9, pp. 129-136.

[20] Shanken, J. (1985) 'Multivariate Tests of the Zero-Beta CAPM', Journal of Financial Economics, vol. 14, pp. 327-348.

[21] Shanken, J. (1992) 'On the Estimation of Beta-Pricing Models', The Review of Financial Studies, vol. 5 (1), pp. 1-33. 
The impact of speculation on the pricing of companies...

[22] Urbański, S. (2011) Modelowanie równowagi na rynku kapitałowym - weryfikacja empiryczna na przykładzie akcji notowanych na Giełdzie Papierów Wartościowych w Warszawie, Prace Naukowe Uniwersytetu Ekonomicznego w Katowicach: Katowice.

[23] Urbański, S. (2012) 'Multifactor Explanations of Returns on the Warsaw Stock Exchange in Light of the ICAPM', Economic Systems, vol. 36 (4), pp. 552-570.

[24] Urbański, S. (2014) 'The Impact of Speculation on the Appropriate Stock Pricing in Light of the CAPM', Author's unpublished works.

[25] Zarzecki, D., Byrka-Kita, K., Wiśniewski, T. and Kisielewska, M. (2004-2005), 'Test of the Capital Asset Pricing Model: Polish and Developer Markets Experiences', Folia Oeconomica Statitiensa, vol. 11-12, pp. 63-84. 